\title{
Paideusis
}

\section{Socratic Virtue Through Thick and Thin}

\section{Paul O'Leary}

Volume 9, Number 1, 1995

URI: https://id.erudit.org/iderudit/1073247ar

DOI: https://doi.org/10.7202/1073247ar

See table of contents

Publisher(s)

Canadian Philosophy of Education Society

ISSN

0838-4517 (print)

1916-0348 (digital)

Explore this journal

Cite this article

O'Leary, P. (1995). Socratic Virtue Through Thick and Thin. Paideusis, 9(1), 3-12.

https://doi.org/10.7202/1073247ar

(c) Paul O'Leary, 1995

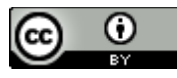

This document is protected by copyright law. Use of the services of Erudit (including reproduction) is subject to its terms and conditions, which can be viewed online.

https://apropos.erudit.org/en/users/policy-on-use/
This article is disseminated and preserved by Érudit.

Érudit is a non-profit inter-university consortium of the Université de Montréal, Université Laval, and the Université du Québec à Montréal. Its mission is to promote and disseminate research.

https://www.erudit.org/en/ 


\section{Socratic Virtue Through Thick and Thin}

\section{Paul O'Leary, University of Western Ontario}

Socrates' dictum that virtue is knowledge means that acquiring an ethically admirable disposition of character, if not simply acquiring a set of true beliefs about the way things are, is, at the very least, a matter of acquiring the capacity to attain such beliefs. However, a virtue is also-or I shall suppose it to be-a disposition to choose or reject actions because they are of a certain ethically relevant kind. ${ }^{1}$ But if we accept a Socratic version of a virtue as a disposition to exercise a certain kind of cognitive capacity, how can it also engage an agent's will, as it must, if a virtue is equally a disposition to make choices about what to do?

On a prescriptivist interpretation, a judgement that an action is of a certain ethically relevant kind reflects the sort of moral principles an agent has chosen to live by. Adopting such principles is not a matter of coming to believe certain "moral facts" but of choosing actions of a certain descriptive kind because they accord with certain formal principles such as universalizability. The moral evaluation of an action is logically separable from its description. Accordingly, viewing the moral virtues in terms of a disposition to exercise a capacity to achieve a certain kind of true belief about our actions mistakenly conflates evaluation and description.

Such a conflation is understandable when we consider that many of the concepts employed in our judgements about actions being of a certain ethically relevant kind involve conjunctions of descriptive and evaluative elements such as murder, betrayal, indebtedness, cruelty, kindness, and rudeness. On a Socratic view, the elements are inseparable so that an agent, in believing that a given act is murder, necessarily takes himself to have reason to avoid doing that action. But, according to the prescriptivist approach, if the descriptive and evaluative elements were inseparable, it would be impossible to make a judgement such as "that is murder" while remaining indifferent to the reason giving force of such a judgement. Yet, such indifference is entirely possible. Such seems to be the case with Pinkie, the main protagonist in Graham Greene's Brighton Rock:

The Boy said slowly, leaning out across the rail into the doubtful rain: "When people do one murder, I've read they sometimes have to do another-to tidy up." The word 'murder' conveyed no more to him than the word 'box,' "collar,' 'giraffe'.,"2

Pinkie suffers from what Hare would call the "so what" syndrome. ${ }^{3}$

Prescriptivism's use of the "so what" syndrome constitutes a serious objection to the Socratic claim that acquiring an ethically admirable disposition of character is a matter of achieving a disposition to exercise a certain kind of cognitive capacity. As I shall try to show, the "so what" attitude does not require us to treat descriptive and evaluative elements as logically separable when we utilize what I shall call "thick" ethical concepts. Such a syndrome cannot be due to an agent's failure to make a commitment from a separable evaluative viewpoint but rather to a failure "to see situations in a specific light, as constituting reasons for acting." 4 However, since my defence of "Socratic virtue" has more than its fair share of twists and turns, it might be useful at this point to erect a few signposts. 
The paper begins by characterizing a certain class of ethical judgements which, although evaluative, can nonetheless be true of actions. When these judgements are true, the agent making them can be said to have ethical knowledge; that is, he or she not only has true beliefs but also, and necessarily, acknowledges these beliefs as reasons for acting. After examining several ways in which the "so what" syndrome -can occur while preserving the Socratic connection between knowledge and the acknowledgement of reasons, the paper then considers how agents come to be disposed to exercise their ethical knowledge. Use is then made of Alisdair MacIntyre's notion of a practice. An argument is put forward to the effect that initiation into certain practices is indispensable to acquiring an ethical disposition. Moreover, acquiring a distinctly ethical outlook means that other non-ethical evaluations of actions which may circumstantially conflict with ethical judgements are silenced. One way in which such silencing occurs is through ethical achievement becoming a basis for an agent's judgement of self-worth. In this way, ethical knowledge can become a central part of a child's developing motivational structure. Finally, the paper makes some concluding remarks about the character of moral education when initiation into certain practices becomes central to it.

\section{Virtue-Related Appraisals}

A virtuous agent, in having the dispositions he or she has, tends to view situations in terms of their ethically relevant features. Characteristics of situations are matters of sizing them up-that is, appraising them. Such appraisals are logically antecedent to making judgements about what, all things considered, one has most reason to do. Because appraisals of situations reflect the dispositions of the agents who make them, let us call appraisals which reflect an ethical outlook "virtue-related appraisals."

There are three initial points I should like to make about virtue-related appraisals so as to help clarify the concerns of this paper. The first is that these appraisals take the form "this is a that"-that is, they serve as a kind of identification. Appraisals may apply not only to actions (e.g., "This act of giving money to a customs official is identical to bribing him") but to character (e.g., "There was at times a silent intensity or even ferocity about the man that alarmed those who came close to him ..."), emotions (e.g., "His gay cynicism had turned into something very like despair."), motives (e.g., "She was still, behind the mask of a young matron, a calculating child .... tormented by an implacable discontent"), and so on.' In what follows, however, I shall be concerned only with virtue-related appraisals of actions and not with how they might apply to these other features of situations even though the latter often have a bearing on the sort of action appraisals an agent will make. Secondly, in allowing virtue-related appraisals to be logically antecedent to an agent's judgements about what he or she has most reason to do, I am taking individual appraisals as providing a reason for acting but not necessarily as providing a decisive reason. Dilemmas occur when different virtue-related appraisals give one reason to do different and, because of the situation, conflicting actions. In what follows, however, I will not enquire into how we might determine in such cases what we have most reason to do. Rather, my concern is with virtue-related appraisals as providing ethical knowledge because they constitute beliefs which, when true, necessarily provide an agent with a reason to act. Finally, in making 
virtue-related appraisals of actions, an agent has at his or her disposal an ethical vocabulary which is diverse and often highly nuanced. The concepts employed within such appraisals can range from certain "thin" (i.e., general and abstract) concepts (e.g., $\mathrm{x}$ is "good," "bad," "right," "wrong," "ought to be done," "ought not to be done") to a "'thicker" (i.e., more specific and concrete) variety (e.g., $x$ is "kind," "courageous," "tactless," "humiliating," "murder," "honest," and so on). In making virtue-related appraisals which utilize "thick" ethical concepts, an agent is relying on both a description and evaluation of the actions to which such appraisals apply. The first question I want to raise then is whether the descriptive and evaluative elements found within appraisals which utilize thick concepts are logically inseparable. If they are as I think they are, we have the beginnings of a case for taking "thick" virtuerelated appraisals of actions as the sort of beliefs which involve a conception of how things are while also and necessarily being constitutive of an agent's reasons for acting.

\section{Anscombe's Grocer}

To what sort of considerations do we need appeal in making a virtuerelated appraisal of an action? On the prescriptivist interpretation of thick ethical concepts, we need to consult both the facts of the matter and our logically separable evaluative standards for making ethical judgements. ${ }^{6}$ However, another more satisfactory view claims that all we need consider in making a justified virtue-related appraisal of an action are the facts of the matter. In her article, "On Brute Facts,"7 Elizabeth Anscombe claims that the fact that a customer ordered potatoes and that the grocer delivered them is enough to justify the belief that the customer owes the grocer a certain sum of money. So appraising the act of giving a certain amount of money to the grocer, as a matter of giving what is owed, does not require for the application of this thick ethical concept an additional appeal to a standard which determines whether an act done under a certain description is a case of acting well. The facts suffice. Similarly, a justified denial that the money is owed to the grocer only requires one to establish either that the customer did not order the potatoes or that the grocer did not deliver them. So, then, the evaluations of actions in terms of those virtuerelated appraisals which make use of thick ethical concepts are based solely upon factual considerations. If certain of our beliefs about what is the case are true, then certain of our appraisals are true and, thus, count as knowledge. The descriptive and evaluative elements in "thick" appraisals of actions are logically inseparable in the way that appraisals as conclusions are logically inseparable from the factual considerations which justify them.

The facts that are relevant to establishing the truth of a particular appraisal of an action depend upon the thick concepts being employed. Whether the act of giving Anscombe's grocer some money is giving what is owed or giving a generous donation will depend upon the existence of different matters of fact even though both acts are matters of acting well. One distinctive advantage of utilizing thick rather than thin ethical concepts in appraising actions is that the sort of facts which need to be cited in justifying a particular appraisal fall within a circumscribed range. 


\section{Knowledge and Reasons}

On the Socratic view put forward in this paper, it is not possible for an agent to know that he owes his grocer some money while failing to acknowledge that he has reason to pay his grocer. Accordingly, if one fails to make such an acknowledgement, then there is a corresponding failure in his knowledge. Such Socratic claims, however, seem singularly unpromising especially in the face of the "so what" syndrome. Thus, it does not seem in the least incredible that an agent may know full well that he owes his grocer money while remaining indifferent to this as a reason for his paying him.

Consider two cases in which an agent does not acknowledge owing the grocer money as a reason for paying him. In the first case, the customer normally does pay his grocer what he owes except when doing so is inconvenient. Such a case could no doubt be viewed as one in which, for the agent, matters of convenience and comfort outweigh the consideration that the money is owed. Such an interpretation, however, is not helpful in this instance since when one appraisal is taken as outweighing another, the outweighed consideration is still acknowledged as a reason. What is needed is an interpretation whereby the agent does not even acknowledge his owing the grocer as a reason. This can be obtained by viewing the agent's appraisal of the payment as inconvenient, not as outweighing the fact that he owes it, but rather as silencing it. Not acknowledging owing the money as a reason is, in this case at least, a matter of silencing the status of an appraisal as a reason. Contrary to the Socratic claim, however, such silencing does not appear to require us to deny that the agent knows that he owed his grocer some money. ${ }^{8}$

In the second case, the "so what" syndrome does not take the form of silencing the status of an appraisal as a reason but rather denies that it is a reason. For example, someone might deny that owing the grocer is a reason for him to give the grocer money since he or she has disavowed the entire practice of buying and selling within which questions of what is and what is not owed, arise. Again, the question emerges as to whether such a denial on the customer's part means, as the Socratic thesis requires that the agent does not know that he owes money.

Are we required to abandon the Socratic connection between knowledge and reasons, when, as in the first case, not acknowledging an appraisal as a reason amounts to silencing it? Notice, however, that in this case silencing "owing someone money" as a reason is not always done but only when paying money is appraised as inconvenient. Nor in this case do we need to claim that the agent has lost his or her cognitive capacity to identify and recognize instances in which the appraisal "is owed" applies. Rather, the silencing of an appraisal comes about in a particular circumstance; it does not destroy but only circumstantially prevents the exercise of the agent's capacity to identify and recognize cases as falling under that appraisal. So, in our first example, although an agent may have knowledge of what it is to owe something to someone else, he or she has it dispositionally but not occurrently. ${ }^{9}$ So, insofar as an agent's not acknowledging an appraisal as a reason is a matter of silencing it, the Socratic claim that such an agent does not know what he is doing is left intact. For he or she does not have occurrent knowledge of the action as falling under the silenced appraisal, even though knowledge of what does fall under it is possessed dispositionally. 
Turn now to the second case. Here the agent denies that a certain appraisal ever gives him reason to do that to which the appraisal applies. Such a denial means that, in the case of the appraisal "is owed," the agent no longer gives money to others "because it is owed." Moreover, he or she never deliberates about what to do in terms of what money is owed to whom. Such questions simply do not arise for that person and, thus, he or she never obtains occurrent knowledge of himself as owing any money to anyone. So, where occurrent knowledge of one's own actions is concerned, denying that a certain appraisal is a reason for him to do something means that such an agent cannot know his own actions in terms of that appraisal. The Socratic connection between knowledge and reasons still remains intact.

In this second case, the agent's denial that "is owed" is a reason for him to do something is linked to his rejection of the practice of buying and selling. Although this rejection means that he no longer understands his own conduct in terms of owing money to others, this does not mean that he cannot understand how that appraisal is a reason for others who continue to engage in the practice of buying and selling. However, if the denial amounts to denying that "is owed" could be a reason at all, then one is require to view "because it is owed" as unintelligible as an explanation of why somebody acted as he or she did. If the Socratic thesis is correct, anyone who found such an explanation unintel'ligible would also not understand what it is to owe money to someone else. Such a person would lack the capacity to identify and recognize what actions fall under that appraisal.

Consider a case in which someone who is completely unfamiliar with the game of baseball is told that a player has moved from one base to another because he has stolen it. No doubt such an explanation would remain unintelligible until some of the rules, tactics, and point of the game have been explained. Until that time, our uninitiated observer would be unable to differentiate between moving from one base to another because it was stolen, because of a walk, because of a balk, or because of a sacrifice fly. The intelligibility of the concepts used to describe and appraise various moves within the game of baseball goes hand-in-hand with understanding the game. One's capacity to identify and recognize what actions fall under which baseball concepts increases as one's understanding of the game increases.

Similar sorts of considerations apply, I believe, in getting others to be able to identify and recognize what actions fall under a variety of virtue-related appraisals. Perhaps the reason why Pinkie, the protagonist, in Brighton Rock thinks as he does is that, like an uninitiated observer of baseball, those practices in which concepts like "murder" get their sense remain opaque to him.

\section{Practices and Dispositions}

In the last section, I tried to show some of the ways in which the "so what" syndrome can occur without undermining the Socratic connection between knowledge and the acknowledgement of reasons. Thus, in cases where a virtue-related appraisal is not acknowledged as a reason since it is silenced, the agent does not have occurrent knowledge of his action even though he may have dispositional knowledge since his capacity to identify and recognize actions as falling under the appraisal is not lost. Similarly, not having occurrent knowledge coupled with the possession of dispositional knowledge occurs when 
not acknowledging an appraisal as a reason is linked to the rejection of a practice in which the appraisal concept plays a role. The only case in which not acknowledging an appraisal as a reason involves an agent not having dispositional knowledge occurs when he or she views the appraisal as unintelligible.

Although these cases may show how the Socratic connection between an agent's knowledge and reasons for action may be preserved despite appearances to the contrary, the first two cases prompt a question about the relation between having ethical knowledge dispositionally and exercising it. But since Socratic virtue is constituted by a disposition to exercise a capacity to identify and recognize actions in virtue-related ways, the obvious question about the ethical upbringing of the young is whether acquiring a virtue requires something in addition to what it takes to acquire the cognitive capacity to identify and recognize actions as being of a certain ethically relevant kind.

In order to get some leverage on this question, suppose we utilize the notion of a practice as characterized by Alisdair MacIntyre in After Virtue. There he says:

By a "practice," I am going to mean any coherent and complex form of socially established co-operative human activity through which goods internal to that form of activity are realised in the course of trying to achieve those standards of excellence which are appropriate to, and partially definitive of, that form of activity, with the result that human powers to achieve excellence, and human conceptions of the ends and goods involved, are systematically extended. Tic-tac-toe is not an example of a practice in this sense, nor is throwing a football with skill; but the game of football is, and so is chess. Bricklaying is not a practice; architecture is. Planting turnips is not a practice; farming is. So are the enquiries of physics, chemistry, and biology, and so is the work of the historian, and so are painting and music. ${ }^{10}$

The importance of the concept of a practice is that it enables Macintyre to offer a partial definition of a virtue. He says:

[A] virtue is an acquired human quality the possession and exercise of which tends to enable us to achieve those goods which are internal to practices and the lack of which effectively prevents us from achieving any such goods. ${ }^{11}$

On his way to reaching this conclusion, Macintyre offers an example of learning to engage in a practice which will help us to understand the conditions under which one acquires an ethical disposition. He writes:

Consider the example of a highly intelligent seven-year-old child whom I wish to teach to play chess, although the child has no particular desire to learn the game. The child does, however, have a very strong desire for candy and little chance of obtaining it. I, therefore, tell the child that, if the child will play chess with me once a week, I will give the child 50 cents worth of candy; moreover, I tell the child that I will always play in such a way that it will be difficult, but not impossible, for the child to win and that, if the child wins, the child will receive an extra 50 cents worth of candy. Thus motivated, the child plays and plays to win. Notice, however, that, so long as it is the candy alone which provides the child with a good reason for playing chess, the child has no reason not to cheat and every reason to cheat, provided he or she can do so successfully. But, so we may hope, there will come a time when the child will find in those goods specific to chess, in the achievement of a certain highly particularly kind of analytical skill, strategic 
imagination, and competitive intensity, a new set of reasons, reasons now not just for winning on a particular occasion, but for trying to excel in whatever way the game of chess demands. Now, if the child cheats, he or she will be defeating not me, but himself or herself. ${ }^{12}$

In becoming disposed not to cheat when playing chess, it is not only crucial that the child learn to recognize and identify the sort of moves which would count as cheating, but that he or she moves from aiming at goods which are external to the game of chess to aiming at those which are internal (e.g., achieving a certain sort of analytical skill). That is, coming to have such a disposition depends upon the child having his or her outlook on chess transformed from viewing the practice solely in terms of its being a tolerable means of obtaining candy to seeing it solely in terms of an exercise in " a certain highly particular kind of analytical skill, strategic imagination, and competitive intensity."13 If this transformation of outlook is complete, the child no longer acknowledges the pleasure of the candy as a reason to cheat when playing chess. This lack of acknowledgement does not require the child to deny that the pleasure of candy is a reason to seek candy. ${ }^{14}$ Rather, it occurs because the chess-related appraisals of conduct in playing chess are held in a way which silence pleasure as a reason when obtaining such pleasure requires cheating. Acquiring the disposition not to cheat when playing chess can come about when the leamer's chess-related appraisals silence other types of appraisals when the latter circumstantially conflict with the achievement of those goods internal to chess.

Although the child's transformed outlook on chess carries with it the acquisition of a disposition not to cheat when playing chess, such an outlook is not a distinctively ethical one. When an agent does have a distinctively ethical outlook on other human beings, their situations, and his or her conduct towards them, the dispositions which constitute such an outlook are not confined in their exercise to a single practice like chess. Nevertheless, there is an instructive similarity between someone who has had his outlook on chess transformed and someone who has acquired a distinctively ethical outlook. For, just as someone whose outlook on chess has been completely transformed is not usually tempted by candy to cheat when playing chess, so, too, an honest person is not usually tempted to refuse to pay what he or she owes others even though it is inconvenient to do so. In both cases, certain types of appraisals silence, though they do not deny, other types of appraisals as reasons when the latter circumstantially conflict with the achievement of goods internal to a practice. Given this similarity, consider what it is about an agent who acquires a transformed outlook on chess that allows those appraisals which give an agent reason to cheat to be silenced. This will provide a useful parallel for understanding the acquisition of a distinctively ethical outlook.

\section{Acquiring an Ethical Outlook}

Suppose when learning to engage in the practice of chess, a student is caught cheating and feels ashamed. Further, suppose that the shame is not based upon appraisals of himself as being stupid enough to get caught but rather on his appraisal of himself as weak for giving into the temptation that the candy presents. In identifying and recognizing the pleasure of eating candy as a temptation, our novice acknowledges such pleasure as a reason for making a 
certain chess move even though such a move is also recognized as cheating; he is considering such a move despite its being cheating. Insofar as the candy is regarded as a temptation and not simply as an opportunity, then the student's outlook on chess is beginning to be transformed from one in which the game is viewed solely as a means to getting candy to one in which only the goods internal to the practice are the ones being sought. In being tempted, however, the student's outlook has not yet been completely transformed. Yet, capitulating to an acknowledged temptation does not necessarily give rise to feelings of shame since failing in this way can be done with equanimity. In being ashamed of himself, however, the student reveals that at least some of his appraisal of his own self-worth is based upon chess-related appraisals of his own conduct in the pursuit of the goods internal to chess. In cheating, he has let himself down.

An agent's appraisal of his or her own self-worth is based upon certain types of appraisal which are used to characterize the sort of conduct which the agent expects of himself. While acknowledged by the agent as providing reasons for his conduct, other types of appraisal may nevertheless not be connected with an agent's estimation of his own self-worth. The more central to a person's sense of self-worth certain types of appraisal become, the less likely it is that he or she will be tempted by other types of appraisal which are not connected to estimations of self-worth. Resorting once more to our chess example, the more pride our novice takes in his or her ability at playing chess, the less likely it is that the pleasure of candy will be acknowledged as a reason to cheat. Certain types of appraisal silence others with which they circumstantially conflict when they, but not the conflicting appraisals, are held as a central basis for the agent's appraisal of his or her own self-worth. 15

It is through learning to engage in a practice like chess and by having a competent and trustworthy chess teacher that it becomes possible for our students to develop an outlook on the game which silences certain other appraisals as reasons to cheat. Being initiated into a practice by a competent and trustworthy teacher does not guarantee that the relevant transformation of outlook will occur. However, without this sort of initiation, appraisals of chess moves remain unintelligible as reasons and, thus, cannot come to be a basis for the agent's appraisal of self-worth. Starting with the inducement of the candy in order to bring about the student's transformation of outlook, the teacher relies upon appealing to whatever pride and shame the student is capable. Thus, good moves are praised, bad moves criticized, while cheating is disparaged and even mocked. If this is to have any effect at all, the student needs to subject himself or herself to the authority of the teacher while also trusting that the teacher will give out the external rewards as promised.

Now, turn to the acquisition of a distinctively ethical outlook. Here, too, learning to engage in certain practices is indispensable to, though not a guarantee of, achieving such an outlook. Some of the practices which are particularly relevant to acquiring a disposition to view one's conduct towards other human beings in terms of virtue-related appraisals are those which, in Macintyre's words, create and sustain human communities. ${ }^{16}$ Among these practices would be the making and sustaining of family life as well as creating and sustaining a polity. What makes leaming to engage in the sustaining of particular forms of human community especially relevant to the formation of a distinctively ethical outlook is that these practices, unlike chess, have as part of 
their internal good the creating and maintaining of specific "thickly" described ties with other human beings. Without being initiated into some of these sorts of practices, virtue-related appraisals would remain unintelligible as reasons to the young. Moreover, without such an initiation, virtue-related appraisals could not even begin to gain a central place in a person's motivational structure, since how well one treats others in sustaining a community could not become a basis for the agent's sense of self-worth.

Unlike being initiated into a practice like chess or even some other forms of human community, initiation into family and civic life does not start at a point where external goods need to be used as an inducement to learn to engage in each form of community. One does not choose one's family or civic ties but is born into them. One does not learn how to appraise actions towards those others with whom one has familial or civic ties from outside these practices before choosing which sort of actions to make one's own. Rather, the capacity to recognize and identify actions as being of a certain virtue-related kind is developed through an agent's own actions being praised or criticised within family or civic life by those whom the novice acknowledges as having competence in such matters. Crucial to turning this capacity into a disposition to view one's own conduct towards others in terms of virtue-related appraisals is the making of this type of appraisal as the agent's own basis for estimations of his or her self-worth. To do this, those who have the authority to raise the young need, along with favourable circumstances, the persuasiveness to get the young "to see situations in a certain light, as constituting reasons for acting."17

\section{Concluding Remarks}

This paper has claimed that the formation of a distinctively ethical outlook requires initiation into those practices which are concerned with the creation and maintenance of human communities. Such initiation involves learning to recognize and identify one's own actions towards others with whom one shares a life in terms of a certain range of thick ethical concepts which are inseparably descriptive and evaluative. Accordingly, in one's ethical formation, one does not leam to occupy a separable evaluative point of view from which to survey and critically judge what will or will not count as a reason for acting. This, however, marks an important difference from prescriptivism, where the existence of a separable evaluative point of view is insisted upon and whose attainment makes it possible to be reflective about conventional ethical beliefs. From the prescriptivist point of view, it is a grave defect of the inseparability thesis that it can lead to the sort of moral education in which one remains uncritically captive to the ethical life of one's community. ${ }^{18}$

Does the inseparability thesis involve an unreflective acceptance of the received opinion as to what we have reason to do or avoid? Yes and no. One objection to a separable evaluative point of view is that it is difficult to see how it can critically determine which of the many descriptions actions may have, are the ones to be selected for evaluation. On the other hand, believing on someone else's authority that actions of given descriptions are the ones we have reason to do or avoid, does, if the one whose word is believed is both competent and trustworthy, give a learner ethically relevant descriptions to which thick ethical concepts apply. But such descriptions do not act as defining properties of various ethical concepts but rather as correct and representative samples of their 
application and on which basis a learner may then carry on to judge new cases. So, then, unreflective acceptance of the authority of others as to what we have reason to do or avoid makes it possible to carry on reflectively within a practice.

In having a virtue, a person is disposed to silence the reason-giving force of other appraisals when they circumstantially conflict with virtue-related ones. In this paper, I have claimed that this feature of an ethical outlook can occur when ethical achievements are part of the basis of agents' appraisal of their own worth. Although this connection between virtue and self-esteem can be forged without engaging upon reflections as to the sort of life one has most reason to live, it does not preclude them. Indeed, the non-reflective sources of the dispositions human beings acquire form a pre-condition for any reflection to have any content. Perhaps, then, we have reason to believe Aristotle when he says that teaching about what sort of life we have most reason to live will be little understood when directed at those who have been badly brought up. 19

\section{Notes}

${ }^{1}$ This formulation is taken from Bernard Williams' Ethics and the Limits of Philosophy (London: Fontana, 1985), 9.

${ }^{2}$ Graham Greene (Harmondsworth, Middlesex: Penguin Books, 1943), 46.

${ }^{3}$ R. M. Hare, Moral Thinking (Oxford: Clarendon Press, 1981), ch. 4.

4John McDowell, "Are Moral Requirements Hypothetical Imperatives?" Proceedings of the Aristotelian Society, Supplementary Volume 52, 1978, 21.

${ }^{5}$ The last three examples are taken from John Banville's Doctor Copernicus (London: Paladin, 1978), 36, 72, 145.

${ }^{6}$ See R. M. Hare, op. cit., 65-78.

${ }^{7}$ To be found in Elizabeth Anscombe's Ethics, Religion and Politics (Minneapolis: University of Minnesota Press, 1981), 22-5.

${ }^{8}$ For the notion of silencing as distinct from outweighing, see John McDowell, op. cit., 26.

${ }^{9}$ The distinction between having knowledge dispositionally and having it occurrently can be found in Aristotle's treatment of incontinence. See the Nichomachean Ethics, 1146b, 31-35.

${ }^{10}$ Alasdair MacIntrye (Notre Dame: University of Notre Dame Press, 1981), 175.

${ }^{11}$ Ibid., 175-6.

${ }^{12} \mathrm{Ibid}$.

${ }^{13}$ Ibid.

${ }^{14}$ Nor do we have here a case in which the pleasure of the candy outweighs other opposing considerations, for this means the pleasure is acknowledged as a reason.

${ }^{15}$ This is only one way in which types of appraisal of one's actions can silence others. In other cases, they do so when an agent makes acting in a certain way a principal aim of his or her life.

${ }^{16}$ MacIntyre, op. cit., 175.

17 Ibid., 21.

${ }^{18}$ R.M. Hare, op. cit., 68-71.

${ }^{19}$ Aristotle, Nichomachean Ethics, 1179b, 25-30. 